\title{
CASE BASED LEARNING: AN ESSENTIAL TOOL IN MEDICAL CURRICULUM FOR TEACHING BIOCHEMISTRY
}

\section{Karanpreet Bhutani* \\ Suvarna Prasad}

\section{Kirti Sharma}

Assistant Professor, Department of Biochemistry, MMIMSR, MMDU, Mullana. *Corresponding Author

Professor \& Head, Department of Biochemistry, MMIMSR, MMDU, Mullana . M.Sc Medical Biochemistry, Department of Biochemistry, MMIMSR, MMDU, Mullana.

\section{Upinder Singh} Orthopaedic Consultant, Prime Hospital, Patiala.

ABSTRACT Introduction: Active learning model using cooperative techniques such as Case Based Learning (CBL) has increased. In CBL, the instructor acts as a facilitator in the construction of knowledge. Clinical Biochemistry is concerned with methodology and interpretation of biochemical tests performed on the body fluids and tissues, to support diagnosis, treatment and monitoring of disease. ${ }^{1}$ Some change in the teaching learning method can enhance the interest of the students in the subject and they can apply the knowledge of the subject in diagnosis, treatment and follow up of a disease in their professional career.

Aims and Objectives:To introduce CBL as teaching learning method and then:-1. Compare score of students by two methods of teaching- Traditional didactic lectures and case based approach.2. Evaluate student's and Faculty's feedback regarding their perception of case based learning.

Method: The study was conducted in the Department of Biochemistry, MMIMSR, Mullana (Ambala) during six months period. 150 First professional MBBS students (Batch 2018-19) of MMIMSR, Mullana were included in the study.Pre and Post Test and prevalidated questionnaire (Based on Likert's scale) were used as tools for data collection. The students were divided into two groups: - Group A ( $n=75$ ) (Study group): case based learning (CBL) was used as teaching learning method. Group B ( $n=75$ ) (Control group): Traditional didactic lecture method was used as teaching learning method.

Result: The Post- test scores of both the learning methods were statistically significantly higher when compared to their respective Pre- test scores. ( $p<0.05$ ). The Post- test score of CBL group was higher than that of Didactic lecture group ( $<<0.05)$. Conclusion: Both faculty and students wanted CBL sessions to be held in future as this makes Biochemistry a very interesting subject .So CBL should be incorporated along with Didactic lectures in the curriculum for MBBS students.

\section{KEYWORDS : Case Based Learning, Biochemistry, Curriculum.}

\section{INTRODUCTION:}

In the undergraduate teaching, there is a general need to develop problem- solving, critical thinking, and communication skills, beyond the learning of content. So in order to achieve successful learning outcomes by undergraduate students, finding effective learning ways is an on-going challenge for educators. One such active learning model using cooperative techniques such as Case Based Learning (CBL) has increased. In CBL, the instructor acts as a facilitator in the construction of knowledge.

Clinical Biochemistry is concerned with methodology and interpretation of biochemical tests performed on the body fluids and tissues, to support diagnosis, treatment and monitoring of disease. ${ }^{1}$ Some change in the teaching learning method can enhance the interest of the students in the subject and they can apply the knowledge of the subject in diagnosis, treatment and follow up of a disease in their professional career.

The case- based format requires students to recall previously covered material to solve clinical cases which are based on clinical practice. ${ }^{2}$

\section{AIMS AND OBJECTIVES:}

To introduce CBL as teaching learning method and then:-

1. Compare score of students by two methods of teachingTraditional didactic lectures and case based approach.

2. Evaluate student's and Faculty's feedback regarding their perception of case based learning.

\section{METHOD:}

This is an interventional and comparative study which was conducted in the Department of Biochemistry, MMIMSR, Mullana (Ambala) during six months period. 150 First professional MBBS students (Batch 2018-19) of MMIMSR, Mullana were included in the study.

Informed written consent was taken from the students. Approval from Institutional ethics committee was taken. The faculty and students were made verse with the CBL method.

Pre and Post Test and prevalidated questionnaire (Based on Likert's scale) were used as tools for data collection.

The students were divided into two groups:-

Group A ( $\mathrm{n}=75)$ (Study group) : Innovative curriculum with case based learning (CBL) was used as teaching learning method.

Group B ( $n=75$ ) (Control group): Traditional didactic lecture method was used as teaching learning method.

Two case scenarios were chosen- Gout and Jaundice.

Group A was given a clinical problem on Gout in which the symptoms were made clear and a set of questions was given following the problem.Group was given time to define and resolve the problem. The facilitator motivated and guided the students for learning and finding solution to the problem.

While Group B was taught the topic by traditional lecture method.

For the second case scenario on Jaundice, a crossover was done. Group A was taught by traditional method and Group B was taught by case based learning method.

A pre-test and post-test was taken on the topics for both groups in form of MCQs. 
Structured feedback questionnaires (which were validated by pilot testing) on acceptability and usefulness of CBL method were taken from both the students and the faculty.

The data was statistically analysed using student's paired and unpaired t-test. A p value of $<0.5$ was taken as significant.

\section{RESULTS:}

The Post- test scores of both the learning methods were statistically significantly higher when compared to their respective Pre-test scores. $(\mathrm{p}<0.05)$

When intergroup comparison of Pre- test score was done, it was statistically non- significant. ( $p>0.05$ ) while the Post- test score of CBL group was higher than that of Didactic lecture group $(\mathrm{p}<0.05)$

Table 5 shows students perception about CBL and Didactic lectures. More than $90 \%$ students believed that CBL helped in understanding the topics better than traditional lectures. Critical thinking was enhanced by CBL and it helped in better clinical correlation of Biochemistry than Didactic lectures. $70 \%$ students believed that CBL enhanced self- directed learning while $95 \%$ believed CBL to be better than Didactic lectures. $100 \%$ students agreed that both CBL and Didactic lectures should be a part of curriculum.

Table 6 shows analysis of Faculty's perception on CBL, 100\% Faculty agreed that it motivated students in learning Biochemistry and CBL should be a part of Curriculum.

Tablel: Comparison of pre-test and post test scores on "Gout"

\begin{tabular}{|l|l|l|l|}
\hline & Pre- test score & Post- test score & p- value \\
\hline CBL group & $11.6 \pm 2.5$ & $15.7 \pm 3.1$ & $<0.05$ \\
\hline Control group & $10.4 \pm 3.1$ & $12.2 \pm 1.7$ & $<0.05$ \\
\hline
\end{tabular}

Table2: Intergroup comparison of pre-test score and posttest score on "Gout"

\begin{tabular}{|l|l|l|l|}
\hline Score & CBL group & Control group & p- value \\
\hline Pre- test & $11.6 \pm 2.5$ & $10.4 \pm 3.1$ & $>0.05$ \\
\hline Post- test & $15.7 \pm 2.3$ & $12.2 \pm 1.7$ & $<0.05$ \\
\hline
\end{tabular}

Table3: Comparison of Pre- test and Post- test scores on "Jaundice"

\begin{tabular}{|l|l|l|l|}
\hline & Pre- test score & Post- test score & p- value \\
\hline CBL group & $9.2 \pm 3.1$ & $13.3 \pm 3.6$ & $<0.05$ \\
\hline Control group & $8.7 \pm 2.4$ & $10.5 \pm 1.4$ & $<0.05$ \\
\hline
\end{tabular}

Table 4: Intergroup comparison of Pre- test score and posttest score on "Jaundice"

\begin{tabular}{|l|l|l|l|}
\hline Score & CBL group & Control group & p- value \\
\hline Pre- test & $9.2 \pm 3.1$ & $8.7 \pm 2.4$ & $>0.05$ \\
\hline Post- test & $13.3 \pm 3.6$ & $10.5 \pm 1.4$ & $<0.05$ \\
\hline
\end{tabular}

Table 5: Student's perception about CBL and Didactic Lectures $(\%)(n=150)$

\begin{tabular}{|l|l|l|l|l|l|}
\hline Variables & Strongly Agree & Agree & Neutral & Disagree & Strongly Disagree \\
\hline Didactic lecture help in understanding of topic & 30 & 50 & 20 & 00 & 00 \\
\hline $\begin{array}{l}\text { CBL helps in understanding the topic better than Didactic } \\
\text { lecture }\end{array}$ & 45 & 54 & 1 & 00 & 00 \\
\hline Critical thinking is enhanced by CBL & 30 & 60 & 10 & 00 & 00 \\
\hline Critical thinking is enhanced by Didactic lecture & 20 & 25 & 20 & 25 & 10 \\
\hline Clinical correlation of Biochemistry is better with CBL & 50 & 40 & 10 & 00 & 00 \\
\hline $\begin{array}{l}\text { Clinical correlation of Biochemistry is better with Didactic } \\
\text { lectures }\end{array}$ & 25 & 20 & 20 & 25 & 10 \\
\hline Self- directed learning by CBL & 30 & 40 & 20 & 05 & 05 \\
\hline Self- directed learning by Didactic lectures & 20 & 10 & 30 & 30 & 10 \\
\hline CBL is better than Didactic lectures & 05 & 90 & 05 & 00 & 00 \\
\hline Both CBL and Didactic lecture should be part of curriculum & 04 & 96 & 00 & 00 & 00 \\
\hline
\end{tabular}

Table 6: Faculty perception (\%) on CBL

Variables

CBL was very useful in understanding topics taken up

CBL is important to develop critical thinking than didactic lectures

CBL motivated students to learn Biochemistry

Group discussion during CBL session was useful

CBL should be a part of curriculum

\section{DISCUSSION:}

CBL aims at teaching content while actively engaging students in real- life case study scenarios, in order to expose students to the scientific process. ${ }^{3}$ CBL can encourage students to: (a) Gather and apply information to solve problems, (b) Facilitate relevant information retention and (c) Refine communication. ${ }^{4}$ It can encourage students to develop the skills necessary for life-long learning. ${ }^{5}$ The present study showed a significant increase in Post-test score after CBL compared to the post- test score after traditional lectures. These results are comparable to other studies which show improved test scores post CBL session. ${ }^{6,7,8} \mathrm{CBL}$ also promoted active learning. This concept was also supported by the results of other studies. ${ }^{9}$ It enhances the ability of the students to work as a team and analyze case histories and find out solution to increase physician competencies, especially in social and cognitive dimensions. ${ }^{10}$

Another important outcome is faculty training and development which will strengthen teaching quality in the future.

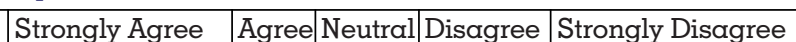

\begin{tabular}{|l|l|l|l|l|}
\hline 80 & 20 & 00 & 00 & 00 \\
\hline 85 & 15 & 00 & 00 & 00 \\
\hline 100 & 00 & 00 & 00 & 00 \\
\hline 90 & 10 & 00 & 00 & 00 \\
\hline 100 & 00 & 00 & 00 & 00 \\
\hline
\end{tabular}

Limitations:

CBL sessions were done only for two topics. We suggest larger study with more case scenarios in Biochemistry curriculum.

\section{CONCLUSION:}

Both faculty and students wanted CBL sessions to be held in future as this makes Biochemistry a very interesting subject and its applied aspect for other clinical subjects is best understood with case scenarios in CBL sessions. So CBL should be incorporated along with Didactic lectures in the curriculum for MBBS students.

\section{REFERENCES}

1. Marek H Dominiczak, contribution of biochemistry to medicine: Medical Biochemistry and Clinical biochemistry Encyclopedia of life support systems.

2. Gravey T, O'Sullivan M, Blake M. Multidisciplinary case- based learning for undergraduate students. Eur J Dent Educ 2000;4(4):165-8.

3. Davies, M. (2004) The successful use of case studies in nutritional biochemistry. Georgia J. sci. 62, 79-86.

4. Biggs, J B., and Tang, C (2011) Teaching for Quality Learning At University, $4^{\text {th }}$ ed., The society for Research into higher Education \& open University Press,Birkshire.

5. Hartfield, P. (2010) Reinforcing Constructivist teaching in advanced level 
Biochemistry through the introduction of case- based learning activities. J. Learn. Des. 3, 20-31.

6. Usha Adiga, Sachinanda Adiga case based learning in biochemistry International Journal of Pharma and Bio Sciences vol 2/issue2/APR-JUN 2011

7. Surpaneni $\mathrm{K} M$ the effect of Integrated Teaching with Case Based Learning (CBL) In the Biochemistry of undergraduate Medical Curriculum Journal of Clinical and Diagnostic Research. 2010 Oct: (5):3058-3063

8. Sandhya Pillai Nair et al. Case Based Learning: A Method for Better Understanding of Biochemistry in Medical Students. Journal of Clinical and Diagnostic Research. 2013: 7(8): 1576-1578.

9. Meyers C, Jones TB. Case Studies. In: Promoting Active Learning: strategies for the College Classroom. San Francisco, CA: Jossey. Bass, 1993; p. 103-19.

10. Bowe CM. Case method teaching: an effective approach to integrate the basic and clinical sciences in the preclinical medical Curriculum. Med Teach 2009 Sep; 31(9):864-841. 